\title{
The Urogynecology Section of the Polish Society of Gynecologists and Obstetricians Guidelines for the diagnostic assessment of pelvic organ prolapse
}

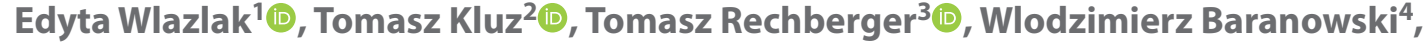 \\ Artur Rogowski ${ }^{5}$, Magdalena E. Grzybowska ${ }^{6}{ }^{(0)}$, Konrad Futyma ${ }^{3}$, \\ Klaudia Stangel-Wojcikiewicz ${ }^{7}{ }^{\mathbb{D}}$, Paulina Pajak ${ }^{8}{ }^{\mathbb{D}}$, Elzbieta Narojczyk-Swiesciak ${ }^{9}{ }^{\oplus}$, \\ Bartlomiej Burzynski ${ }^{10}$, , Radoslaw Maksym ${ }^{11}$, Grzegorz Surkont ${ }^{1}(\mathbb{D}$ \\ ${ }^{1}$ Department of Operative Gynecology and Gynecologic Oncology, $1^{\text {st }}$ Department of Gynecology and Obstetrics, \\ Medical University of Lodz, Poland \\ ${ }^{2}$ Department of Gynecology, Gynecology Oncology and Obstetrics, Institute of Medical Sciences, \\ Medical College of Rzeszow University, Poland \\ ${ }^{3} 2^{\text {nd }}$ Department of Gynecology, Medical University of Lublin, Poland \\ ${ }^{4}$ Department of Gynecology and Gynecological Oncology, Military Medical Institute, Warsaw, Poland \\ ${ }^{5}$ Department of Minimally Invasive and Endoscopic Gynecology, Military Institute of Medicine, Legionowo Hospital, \\ Warsaw, Poland \\ ${ }^{6}$ Department of Gynecology, Gynecological Oncology and Gynecological Endocrinology, Medical University of Gdansk, Poland \\ ${ }^{7}$ Department of Gynecology and Oncology Jagiellonian University Medical College, Cracow, Poland \\ ${ }^{8}$ Department of Obstetrics and Gynecology, Multidisciplinary Hospital Warsaw-Miedzylesie, Warsaw, Poland \\ ${ }^{9} 2^{\text {nd }}$ Department of Obstetrics and Gynecology, The Center of Postgraduate Medical Education, Bielanski Hospital, \\ Warsaw, Poland \\ ${ }^{10}$ Department of Rehabilitation, Faculty of Health Sciences in Katowice, Medical University of Silesia, Katowice, Poland \\ ${ }^{11}$ Department of Procreational Health, The Center of Postgraduate Medical Education, Warsaw, Poland
}

\begin{abstract}
Objectives: The aim of the team appointed by the Board of the Urogynecology Section of the Polish Society of Gynecologists and Obstetricians (PSGO) was to develop this interdisciplinary Guideline for the diagnostic assessment of pelvic organ prolapse (POP) in women, based on the available literature, expert knowledge and opinion, as well as everyday practice.

Material and methods: A review of the literature, including current international guidelines and earlier PSGO recommendations (2010-2020) about POP, was conducted.

Results: The steps of the diagnostic assessment for patients with POP, subdivided into initial and specialized diagnostics, have been presented. Indications for specialized diagnostic assessment have also been listed. In case of surgical treatment, the patient may be referred solely based on the initial diagnostics or after certain elements of the specialized diagnostics have been completed.

Conclusions: Due to inconclusive data, the scope of the diagnostic process for POP is individualized for each patient and depends on patient-reported symptoms, initial diagnostic findings, surgical history, management plan, availability of the equipment, and cost.
\end{abstract}

Key words: pelvic organ prolapse; diagnostics; USG; MRI

Ginekologia Polska 2022; 93, 4: 334-340

\section{Corresponding author:}

Artur Rogowski

Department of Minimally Invasive and Endoscopic Gynecology, Military Institute of Medicine, Legionowo Hospital, Warsaw, Poland

phone: 604060090, e-mail: arogowski@op.pl

Received: 21.09.2021 Accepted: 26.09.2021 Early publication date: 5.01.2022

This article is available in open access under Creative Common Attribution-Non-Commercial-No Derivatives 4.0 International (CC BY-NC-ND 4.0) license, allowing to download articles and share them with others as long as they credit the authors and the publisher, but without permission to change them in any way or use them commercially. 


\section{INTRODUCTION}

Pelvic organ prolapse (POP) is the downward descent of the vagina and/or uterus, which may be accompanied by the prolapse of the lower urinary tract, small intestine and rectum, with or without the associated complaints [1].

POP affects approximately $50 \%$ of all women. It has been estimated that $6-20 \%$ of women will have undergone surgical repair for POP by the age of 80 . Comprehensive diagnostics is the prerequisite of the optimal conservative and surgical treatment. Depending on the surgical technique and the duration of the follow-up, recurrence rates after surgical repair for POP range from $1 \%$ to $29 \%$. Diagnostic errors may have a negative effect on the patient-perceived treatment outcome and POP reoperation rates. Comprehensive diagnostics for POP should focus not only on the anatomical assessment but also on impact of the prolapse on symptoms, quality of life, and sexual function. Determination of the odds ratio for a favorable outcome allows the patient to make an informed decision and choose between conservative or surgical management [2-6]. POP repair significantly improves the quality of patient life, but anatomical success may not ensure complete resolution of all symptoms [7-10].

\section{Objectives}

The aim of the team appointed by the Board of the Urogynecology Section of the Polish Society of Gynecologists and Obstetricians (PSGO) was to develop this Guideline for the diagnostic assessment of POP in women, using the available literature, expert knowledge and opinion, as well as everyday practice.

\section{MATERIAL AND METHODS}

The literature about pelvic organ prolapse, including current international guidelines, was reviewed. Earlier PSGO guidelines (2010-2020) were used. Attention was paid to the level of evidence and degree of recommendation of the available data sources. If the literature source seemed insufficient, consensus expert opinions were used.

\section{GUIDELINE}

The diagnostic assessment for POP has been subdivided into initial and specialized diagnostics. Identification of the patients who should be referred for specialized testing is an important goal of the initial assessment. Specialized diagnostics is recommended to patients with recurrent urinary tract infections, pyuria, urinary retention in the pelvicalyceal system, nephrolithiasis, hematuria and erythrocyturia (symptomatic or detected during testing), concomitant pain complaints of unclear etiology, suspicion of tumor in the bladder, urethra, or the lesser pelvis. Patients after urogynecologic surgery, women with POP and concomitant stress urinary in- continence (SUI), post-void residual and obstructive defecation may also be referred to specialized diagnostics. Patients with ambiguous symptoms and those in whom the uterus and the vagina cannot be repositioned also require complex diagnostic testing [11-16]. Women with unsuccessful surgical repair may be reoperated based on the results of the initial tests or may be referred to specialized diagnostics. It is recommended that the patient has an empty bladder and, if feasible, an empty rectum, for pelvic organ prolapse (POP) assessment. On the other hand, UI testing should be performed with adequately full bladder $[13,14,17]$.

\section{Initial diagnostics}

The initial diagnostic process encompasses components listed below.

1. Medical history

Collection of gynecologic, urogynecologic, obstetric and general medical history is vital for the urogynecologic diagnostic assessment. Its goal should be to recognize patient-reported complaints and their effect on the quality of patient life and sexual function. It is essential to establish which complaints are the most bothersome for the patient [18-20].

2. Urine analysis

If up-to-date urine analysis results are not available, general urine analysis (and culture test, if indicated) is recommended.

3. Clinical evaluation

4. Post-void residual (PVR)

PVR volume may be measured using ultrasound or catherization. It should not exceed $50-100 \mathrm{~mL}$. It is important to check whether PVR lowers or resolves after the reposition of prolapse. Typically, a pessary is used to support the vagina or the uterus (see pessary test) $[13,14,21]$.

5. Urinary incontinence diagnostics

6. Pessary test

7. Gynecological ultrasound is performed as an adjunct test to the bimanual exam

8. Pelvic floor ultrasound in many centers is performed only after the patient has been referred for specialized diagnostics. However, it is more often treated as the standard component of the initial diagnostic process [3, 22-24]

9. In women with POP, especially stages 3 and 4 pelvic organ prolapse quantification scale (POP-Q scale), kidney ultrasound is often performed to evaluate urinary retention [14]

After the initial diagnostics, the patient should be informed about the available non-surgical treatment methods as well as risk factors for surgery failure and the occurrence of de novo SUI symptoms. If surgery is the desired course of action, the patient may be referred based on the results 
of the initial tests. It is also possible to perform elective surgery after certain tests from the specialized diagnostics have been performed.

\section{Specialized diagnostics}

The scope of specialized diagnostic testing needs to be individually adjusted to patient needs. The choice of methods depends on patient-reported symptoms, initial diagnostic findings, management plan, availability of the equipment, and costs.

Certain tests performed during the initial diagnostic assessment may be repeated during specialized evaluation. The specialized diagnostic assessment for POP typically includes the following:

1. ultrasound,

2. urodynamic testing,

3. urethrocystoscopy,

4. magnetic resonance imaging (MRI),

5. computed tomography (CT),

6. defecography $[14,25]$.

\section{GUIDELINE REVIEW Initial diagnostics}

1. Medical history

While collecting urogynecologic medical history, attention should be paid to all complaints which may be associated with POP. Pain complaints should be discussed before surgical intervention. It is vital to establish the leading symptoms, which the patient wishes to eliminate in the first place, and their negative impact on the quality of life (treatment goal) [14].

Pelvic organ prolapse is asymptomatic in many women. The affected patients often fail to notice POP, even if it is clearly visible to the trained eye of the specialist. The most common POP-related symptoms include:

- a vaginal lump or bulge,

- a dragging sensation,

- the feeling of discomfort and heaviness within the lesser pelvis and the lower abdomen,

- bleeding from the vaginal decubitus,

- discomfort and pain in the lumbar area [1, 3].

Negative effect on micturition, resulting from bent or compressed urethra, may manifest as inability or difficulty to start voiding, weak urine stream, inability to start urine stream without repositioning the prolapse, the sensation of incomplete emptying of the bladder, straining or change of position to empty the bladder, post-void residual, and recurrent urinary tract infections, sometimes complicated with urosepsis. POP may be the cause of frequency, urgency, and urinary incontinence $[1,26,27]$.

POP within the posterior compartment may be manifested by difficult defecation, constipation, tenesmus, gas and fecal incontinence. Some patients are forced to apply pressure to the rectum from the side of the vagina during defecation [1, 14, 28].

The following risk factors for POP recurrence should be investigated during the diagnostic assessment:

- familial history of POP,

- higher body mass index (BMI),

- chronic constipation,

- POP: stages 3 and 4 POP-Q [5, 29].

Standardized questionnaires, especially those which have been validated in a given language, may be used to analyze the symptoms. The visual analogue scale (VAS) is an undemanding tool for assessing the effect of POP on the quality of patient life. The patient determines POP-related bother on the 10-point VAS scale, with 0 for 'not at all bothersome' and 10 for 'extremely bothersome'. Also, various surveys may be used. Sexually active women report negative effect of POP on their sexual function, especially as the consequence of weakened vaginal muscles and vaginal prolapse. POP may be the cause of pain complaints and episodes of urinary incontinence during sexual activity (coital incontinence). Also, the occurrence of the symptoms of the genitourinary syndrome of menopause (GSM), and whether they affect the complaints during sexual activity, should be addressed while collecting medical history. Special surveys, which assess the impact of POP on patient-reported sexual function and satisfaction, may also be used $[13,18-20]$.

2. Clinical assessment

Clinical assessment encompasses gynecologic exam to detect symptoms of infection within the vulva and vagina, as well as pelvic disorders. Peri- and post-menopausal women may be evaluated for the symptoms of vulvovaginal atrophy (VVA) using the Vaginal Health Index (VHI) [30, 31].

POP assessment is supposed to establish the level, type and stage of the defect of the pelvic floor and its impact on the reported complaints. Each compartment of the pelvic floor should be evaluated separately, which is possible if bivalve speculum of adequate length and width is used. When assessing the anterior compartment, it is important to differentiate between the central and the lateral s. paravaginal defect. It has been estimated that the minimal straining duration for the Valsalva maneuver should be five seconds. In some cases, the Valsalva maneuver cannot be performed correctly as fear of gas or urine leakage activates strong muscle resistance in the patient. Sometimes, it may be helpful to conduct gynecologic examination during straining in standing position. If the symptoms do not correlate with the clinical findings, it is prudent to repeat the test on another day, in the afternoon or evening. In some cases, it is recommended to determine patient eligibility for the type of the procedure immediately before surgery, after sedation. The POP-Q scale is most used to ensure an objec- 
tive test result. However, some specialists believe it to be overly complicated and time-consuming, so a simplified POP-Q scale has been devised [13, 32].

A clinical-anatomical classification, which allows to correlate the defects depending on the level of support according to the DeLancey scale, may also be used to evaluate POP:

- Level I - responsible for the attachment of the uterus and the vaginal vault to pelvic floor structures and the bony sacrum with the use of the uterosacral, pericervical and cardinal ligaments, and their extension (paracolpia) to the upper one-third of the vagina, which form the pericervical ring; an injury is the cause of uterine prolapse, enterocele as well as cystocele with an apical defect,

- Level II - paracolpia of the middle part of the vagina are attached sideways to the tendinous arch and levator ani fascia, this level also includes the pericervical and rectovaginal fascia; the injury is manifested as lateral cystocele (central and/or lateral defect) and rectocele,

- Level III - the lower part of the vagina is connected to the tendinous perineum, levator ani muscles, and urogenital diaphragm fascia (perineal fascia); the injury results in ureterocele or a central defect of the tendinous perineum [13].

On palpation, it is possible to assess the following:

- vaginal adhesions,

- painful sites, without palpation and on palpation,

- injury to the puborectalis muscle,

- resting tone (RT) of the puborectalis muscle, e.g., using a 6-point scale (Tab. 1),

- ability to perform pelvic floor muscle contractions (PFMC), using a 6-point Oxford scale or pelvic floor ultrasound (Tab. 2),

- anal sphincter in patients with obstructed defecation and fecal incontinence $[22,33,34]$.

The Oxford scale allows to identify patients who are unable to activate pelvic floor muscles and those who, when attempting to contract the pelvic floor muscles, in fact lower them. Those patients should be referred to a physiotherapist to learn proper pelvic floor muscle activation.

Resting tone (RT) scale is a useful tool to identify patients with hypertonic pelvic floor muscles, which may accompany vaginismus, vulvodynia, or chronic pelvic pain syndrome.

Palpation to assess injury within the puborectalis muscle consists in the evaluation of the muscle continuity on both sides of the pubic symphysis. Avulsion is confirmed in the absence of muscle continuity or complete muscle absence on palpation. The examination is performed with the index finger of the dominant hand, parallel to the urethra, with the fingertips positioned towards the bladder neck. The fingertips need to be rotated towards the lower arm of the pubic symphysis and the patient must be instructed to contract

\begin{tabular}{|l|l|}
\hline \multicolumn{2}{|l|}{ Table 1. Grading of puborectalis muscle resting tone } \\
\hline Grade & Description \\
\hline 0 & Muscle not palpable \\
\hline 1 & $\begin{array}{l}\text { Muscle palpable but very flaccid, wide hiatus, minimal } \\
\text { resistance to distension }\end{array}$ \\
\hline 2 & Hiatus wide but some resistance to distension \\
\hline 3 & $\begin{array}{l}\text { Hiatus fairly narrow, fair resistance to palpation but easily } \\
\text { distended }\end{array}$ \\
\hline 4 & $\begin{array}{l}\text { Hiatus narrow, muscle can be distended but high } \\
\text { resistance to distension, no pain }\end{array}$ \\
\hline 5 & $\begin{array}{l}\text { Hiatus very narrow, no distension possible, 'woody' feel, } \\
\text { possibly with pain: 'vaginismus' }\end{array}$ \\
\hline
\end{tabular}

\begin{tabular}{|l|l|}
\hline \multicolumn{2}{|l}{ Table 2. Modified Oxford Score } \\
\hline Grade & Muscle response \\
\hline 0 & Nil \\
\hline 1 & Flicker \\
\hline 2 & Weak \\
\hline 3 & Moderate, slight lift of the examiners finger, no resistance \\
\hline 4 & $\begin{array}{l}\text { Good, sufficient to elevate the examiner's finger against } \\
\text { light resistance }\end{array}$ \\
\hline 5 & $\begin{array}{l}\text { Strong, sufficient to elevate the examiner's finger against } \\
\text { strong resistance }\end{array}$ \\
\hline
\end{tabular}

the muscles of the lesser pelvis. Pelvic floor ultrasound is performed to assess damage to the puborectalis muscle in more detail [34-36].

3. Urinary incontinence diagnostics

UI diagnostics during the first stage of diagnosis and management of POP is of crucial importance. It facilitates the choice of the optimal course of action. It also plays a role in patient satisfaction with therapy, among others, their understanding of why Ul symptoms persisted, appeared de novo, or intensified after surgical or non-surgical management. Apart from excluding bladder emptying disorders, the diagnostics of SUI and occult SUI is important in patients about to undergo surgery. Symptoms of occult SUI are found in approximately $30 \%$ of patients with POP [1, 23].

In case of conservative management (e.g., pessary) without the diagnostics of occult SUI, it is necessary to educate the patient about occult SUI, whose symptoms may appear immediately after pessary placement. Concomitant POP and SUI typically require the use of other methods of conservative therapy. A patient who has been diagnosed with occult SUI may choose another course of action as far as treatment is concerned [14, 37].

The choice of diagnostic methods for Ul in patients with POP requires an individualized approach. Methods which may be applicable in UI diagnostics have been discussed elsewhere, in a separate PSGO Guideline. 
4. Pessary test $[13,17,21,38,39]$

A pessary test may be useful in the diagnosis of occult SUI, to detect the cause of post-void residual, to diagnose patients symptoms which do not correspond with the clinical test results, or those with atypical complaints. A properly fitted pessary, one which supports the uterus or the vagina and causes no discomfort, is selected. The pessary is inserted either solely for the purpose of the diagnostic test in the office and removed immediately afterwards, or it is left in place for a few days, during which the patient conducts various observations at home and in workplace environment.

In patients with adequately full bladder, a cough test is performed in a sitting or standing position after the placement of the pessary, in order to diagnose SUI. During pelvic floor ultrasound, an additional assessment of the funneling of the internal urethral meatus within the proximal, i.e., subvesical segment of the urethral meatus - urethrovesical junction, may also be performed. In patients with an empty bladder, the pessary is inserted into the vagina for a few days and the patient is instructed to monitor continence and keep a micturition diary.

In patients with PVR of $>100 \mathrm{~mL}$, after the pessary is fitted, PVR volume should be measured again after another micturition. If POP is the cause of micturition disorders, PVR volume after micturition with pessary will be significantly lower or the symptom will resolve altogether. In case of doubt, it is advisable to repeat the pessary test several times.

When in doubt whether the symptoms are POP-related, it is recommended that the patient uses the pessary for several days. If the symptoms resolve or diminish significantly, the chance for symptom resolution after surgical repair remains high.

In case of occult SUI, the vagina may be supported using the examiner's fingers or a bivalve speculum during the stress test.

5. Ultrasound diagnostics has been discussed in the specialized diagnostics section of the manuscript.

\section{Specialized diagnostics}

Matters concerning the collection of medical history, urine analysis, clinical evaluation, pessary test and post-void residual evaluation have already been addressed in this Guideline.

1. Ultrasonography

Transvaginal ultrasound as well as urinary tract ultrasound for the assessment of urinary retention are recommended before POP surgery [14].

Ultrasound evaluation of the pelvic floor (pelvic floor ultrasound - PFU, pelvic floor sonography — PFS) allows visualization of the pelvic organs and structures. Its advantages include equipment availability, low cost, dynamic assessment of the pelvic floor, the possibility to instruct the patient and to perform multiple repetitions of the test during straining and PFMC. The quality of the image depends on the skill of the person performing the examination. The resolutions are inferior to those obtained by MRI. Pelvic floor ultrasound may be performed using various probes and techniques. So far, a lot of data about POP diagnostics has been obtained using 2D, 3D and 4D ultrasound with a perineal pelvic floor ultrasound performed with transabdominal probe (PFU-TA). The possibility of evaluating the puborectalis muscle and urogenital hiatus is the main advantage of the PFU-TA.

The results of the studies indicate that complete tearing away of the puborectalis muscle from its insertion in bone (avulsion) after vaginal delivery and hiatal enlargement to $>25 \mathrm{~cm}^{2}$ (ballooning) are both risk factors for POP and POP recurrence after surgical repair. Some authors question the possibility to detect avulsion properly on ultrasound. Ultrasound evaluation may be useful in the assessment of urethral mobility, differentiation between cystocele and cysts, true rectocele, that is a defect of rectovaginal septum or Denonvillier's fascia (incomplete bowel emptying, straining during evacuation), and abnormally distensible intact rectovaginal septum (only POP), a combined recto-enterocele, isolated enterocele, or rectal intussusception. The ultrasound of the pelvic floor also allows to visualize synthetic materials (e.g., a mesh) and their location, mobility, folding, and dislodgement of the mesh arms. It is challenging to evaluate biological materials during an ultrasound test $[12,14,17,23-25,28,40,41]$.

At present, we lack conclusive data to recommend pelvic floor ultrasound before every POP repair in all centers. Some specialists still perform the test routinely before every intervention. In typical cases, NICE does not recommend pelvic floor ultrasound before surgical and non-surgical management. According to the latest NICE guideline, ultrasound diagnostics does not bring additional benefits and waiting for the test may cause unnecessary delay in treatment [42].

Pelvic floor testing may be the source of useful information in patients after unsuccessful urogynecologic surgeries $[3,14,40]$.

2. Urodynamic testing

Detailed recommendations for performing urodynamic tests have been presented in the Guidelines of the Urogynecology Section of PSGO. At present, the literature offers no unambiguous evidence of the benefits of routine urodynamic testing before primary surgery for POP. Urodynamic testing may be performed in patients after unsuccessful urogynecologic procedures and in those with POP and symptoms of concomitant $\mathrm{UI}$ and overactive bladder, or with inconclusive lower urinary tract symptoms. In some centers, urodynamic testing is treated as a standard element of the diagnostic assessment before every urogynecologic procedure, despite the absence of data confirming its role in treatment outcome [14, 26, 27, 43-45]. 


\section{Urethrocystoscopy}

Urethrocystoscopy is recommended in select cases. The test allows to detect tumors, urolithiasis, foreign bodies in the urethra and the bladder (e.g., s polypropylene sling and mesh) [46-48].

\section{Magnetic Resonance Imaging (MRI)}

Dynamic MRI provides a clearer visualization of the anatomic structures as compared to pelvic floor ultrasound. It generates static and dynamic images (e.g. during PFMC). Regardless, MRI is rarely used in the diagnosis of POP for several reasons. It is not a real-time test. During the test, it is difficult to monitor whether the patient performs PFMC adequately or whether she coactivates the levator ani muscle. Few MRI systems allow testing of the sitting or standing patient. POP test requires ultra-fast acquisition, which is costly, of limited availability, and negatively affects image resolution $[14,49]$.

\section{Computed tomography (CT)}

CT may be used in the diagnostic assessment of the upper urinary tract in patients with post-void residual [14].

\section{Defecography}

Defecography (an X-ray test with contrast agent), in exceptional cases is used in patients with constipation, obstructed defecation combined with fecal incontinence, or fecal incontinence after defecation. The diagnostics of bowel complaints had been discussed elsewhere $[25,50]$.

\section{SUMMARY}

Proper diagnostics in patients with pelvic organ prolapse is essential in order to choose optimal therapeutic management, conservative or surgical. Establishing the odds for a successful outcome and the risk factors allow the physician and the patient to make the decision about the optimal course of action, which will meet patient expectations about symptom alleviation and improved quality of life.

Considering inconclusive data, the scope of diagnostic tests is tailored to the individual needs of the patient. The scope of POP diagnostics depends on patient-reported symptoms, results of the earlier, initial diagnostic tests, surgical history, management plan, availability of the equipment and cost.

After test completion and before commencement of the treatment, it is necessary to inform the patient that none of the available methods for POP management will ensure complete symptom resolution. Effective POP therapy (especially in advanced POP), using non-surgical or surgical methods, often results in significant improvement or symptom resolution. However, in some patients, a satisfactory outcome of POP treatment may not necessarily correspond to equally satisfying effect on the bothersome symptoms. It is essential to inform the patient that the effect of POP surgery on pain complaints, UI, OAB, post-void residual, difficulty with emptying the bladder, and other symptoms of the lower urinary tract, remains unpredictable. After elective and successful surgery, the symptoms may persist or intensify, not to mention that de novo symptoms may appear as well.

\section{Conflict of interest}

All authors declare no conflict of interest.

\section{REFERENCES}

1. Dietz HP. Pelvic organ prolapse - a review. Royal Australian College of General practition-ers. 2015; 7: 446-452.

2. Christopher $M$, Baessler K, Barber M. et al. Pelvic Organ Prolapse surgery. In: Abrams P, Cardozo L, Wagg A, Wein A. ed. Incontinence, 6th edition. ICUD ICS 2017: 1871-2007.

3. Shek KL, Dietz HP. Assessment of pelvic organ prolapse: a review. Ultrasound Obstet Gynecol. 2016; 48(6): 681-692, doi: 10.1002/uog.15881, indexed in Pubmed: 26865209.

4. Surkont G, Wlaźlak E, Dunicz-Sokolowska A, et al. [The efficacy of SUI treatment with Burch colposuspension evaluated with use of ITT analysis]. Ginekol Pol. 2007; 78(5): 378-380, indexed in Pubmed: 17867329.

5. Friedman T, Eslick GD, Dietz HP. Risk factors for prolapse recurrence: systematic review and meta-analysis. Int Urogynecol J. 2018; 29(1): 13-21, doi: 10.1007/s00192-017-3475-4, indexed in Pubmed: 28921033.

6. Pająk P, Wlaźlak E, Sobkiewicz B, et al. Pessary w leczeniu dolegliwości uroginekologicznych. Ginekologia i Perinatologia Praktyczna. 2018; 3(4): 143-148.

7. Barber MD, Brubaker L, Nygaard I, et al. Pelvic Floor Disorders Network. Defining success after surgery for pelvic organ prolapse. Obstet Gynecol. 2009; 114(3): 600-609, doi: 10.1097/AOG.0b013e3181b2b1ae, indexed in Pubmed: 19701041

8. Antosh D, Iglesia C, Vora $S$, et al. Outcome assessment with blinded versus unblinded POP-Q exams. Am J Obstet Gynecol. 2011; 205(5): 489.e1-489.e4, doi: 10.1016/j.ajog.2011.07.007.

9. Ellerkmann RM, Cundiff GW, Melick CF, et al. Correlation of symptoms with location and severity of pelvic organ prolapse. Am J Obstet Gynecol. 2001; 185(6): 1332-7; discussion 1337, doi: 10.1067/mob.2001.119078, indexed in Pubmed: 11744905.

10. Bradley CS, Nygaard IE. Vaginal wall descensus and pelvic floor symptoms in older women. Obstet Gynecol. 2005; 106(4): 759-766, doi 10.1097/01.AOG.0000180183.03897.72, indexed in Pubmed: 16199633.

11. Spaczyński M. Rekomendacje Polskiego Towarzystwa Ginekologicznego w sprawie dia-gnostyki i leczenia nietrzymania moczu u kobiet. Gin Prakt. 2005; 86: 45-53.

12. Dietz HP. Ultrasound in the assessment of pelvic organ prolapse. Best Pract Res Clin Obstet Gynaecol. 2019; 54: 12-30, doi: 10.1016/j.bpobgyn.2018.06.006, indexed in Pubmed: 30082146.

13. Diaz DC, Robinson D, Bosch R. et al. Initial assessment of urinary incontinence in adult male and female patients. In: Abrams P, Cardozo L, Wagg A, Wein A. ed. Incontinence, 6th edition. ICUD ICS 2017: 513-556.

14. Khullar V, Amarenco G, Doumouchtsis SK. et al. Imaging, Neurophysiological Testing and Other Tests. In: Abrams P, Cardozo L, Wagg A, Wein A. ed. Incontinence, 6 th edition. ICUD ICS 2017: 671-804.

15. Grzybowska ME, Wydra D. 24/7 usage of continence pads and quality of life impairment in women with urinary incontinence. Int J Clin Pract. 2019; 73(8): e13267, doi: 10.1111/ijcp.13267, indexed in Pubmed: 30230139.

16. Grzybowska ME, Wydra D, Smutek J. Analysis of the usage of continence pads and help-seeking behavior of women with stress urinary incontinence in Poland. BMC Womens Health. 2015; 15: 80, doi: 10.1186/s12905015-0238-6, indexed in Pubmed: 26423398.

17. Wlaźlak E, Kluz T, Surkont G, et al. Urethral funneling visualized during pelvic floor sonography - analysis of occurrence among urogynecological patients. Ginekol Pol. 2018; 89(2):55-61, doi: 10.5603/GP.a2018.0010, indexed in Pubmed: 29512808.

18. Grzybowska ME, Griffith JW, Kenton K, et al. Validation of the Polish version of the Pelvic Floor Distress Inventory. Int Urogynecol J. 2019; 30(1): 101-105, doi: 10.1007/s00192-018-3715-2, indexed in Pubmed: 30003284. 
19. Grzybowska ME, Piaskowska-Cala J, Wydra DG. Polish translation and validation of the Pelvic Organ Prolapse/Urinary Incontinence Sexual Questionnaire, IUGA-Revised (PISQ-IR). Int Urogynecol J. 2019; 30(1): 55-64, doi: 10.1007/s00192-017-3539-5, indexed in Pubmed: 29288345.

20. Grzybowska ME, Wydra DG, Smutek J. Validation of the Polish version of the Pelvic Organ Prolapse/Urinary Incontinence Sexual Questionnaire. Int Urogynecol J. 2016; 27(5): 781-786, doi: 10.1007/s00192-015-2883-6, indexed in Pubmed: 26564223.

21. Petri E. Czy kolposuspensja wciąż znajduje zastosowanie we współczesnej praktyce klinicz-nej. Medycyna Praktyczna - Ginekologia i Położnictwo. 2019; 5: 55-67.

22. Wlaźlak E, Surkont G, Shek KaL, et al. Can we predict urinary stress incontinence by using demographic, clinical, imaging and urodynamic data? Eur J Obstet Gynecol Reprod Biol. 2015; 193: 114-117, doi: 10.1016/j. ejogrb.2015.07.012, indexed in Pubmed: 26291686.

23. Wlaźlak E, Viereck V, Kociszewski J, et al. Role of intrinsic sphincter deficiency with and without urethral hypomobility on the outcome of tape insertion. Neurourol Urodyn. 2017; 36(7): 1910-1916, doi: 10.1002/nau.23211, indexed in Pubmed: 28139863.

24. Wlaźlak E, Kluz T, Kociszewski J, et al. The analysis of repeatability and reproducibility of bladder neck mobility measurements obtained during pelvic floor sonography performed introitally with 2D transvaginal probe. Ginekol Pol. 2017; 88(7): 360-365, doi: 10.5603/GP.a2017.0068, indexed in Pubmed: 28819940.

25. Schachar J. Midpubic Line to Stage Pelvic Organ Prolapse by MRI Defecography As Compared to POP-Q. Obstetrics \& Gynecology International Journal. 2014; 1(2), doi: 10.15406/ogij.2014.01.00011.

26. Wróbel AF, Kluz T, Surkont $G$, et al Novel biomarkers of overactive bladder syndrome. Ginekol Pol. 2017; 88(10): 568-573, doi: 10.5603/GP.a2017.0102, indexed in Pubmed: 29192418.

27. Wróbel A, Kluz T, Surkont $G$, et al. Perspectives for the pharmacological treatment of overactive bladder syndrome. Ginekol Pol. 2017; 88(9): 504-508, doi: 10.5603/GP.a2017.0092, indexed in Pubmed: 29057437.

28. Rojas RG, Wong V, Shek K, et al. Impact of levator trauma on pelvic floor muscle function. Int Urogynecol J. 2013; 25(3): 375-380, doi: 10.1007/s00192-013-2226-4.

29. Young N, Atan IK, Rojas RG, et al. Obesity: how much does it matter for female pelvic organ prolapse? Int Urogynecol J. 2018; 29(8): 1129-1134, doi: 10.1007/s00192-017-3455-8, indexed in Pubmed: 28914337.

30. Nappi RE, Martini E, Cucinella L, et al. Addressing Vulvovaginal Atrophy (VVA)/Genitourinary Syndrome of Menopause (GSM) for Healthy Aging in Women. Front Endocrinol (Lausanne). 2019; 10: 561, doi: 10.3389/fendo.2019.00561, indexed in Pubmed: 31496993.

31. Mothes AR, Runnebaum M, Runnebaum IB. An innovative dual-phase protocol for pulsed ablative vaginal Erbium:YAG laser treatment of urogynecological symptoms. Eur J Obstet Gynecol Reprod Biol. 2018; 229: 167-171, doi: 10.1016/j.ejogrb.2018.08.010, indexed in Pubmed: 30199815.

32. Lemos $\mathrm{N}$, Korte JE, Iskander $\mathrm{M}$, et al. Center-by-center results of a multicenter prospective trial to determine the inter-observer correlation of the simplified POP-Q in describing pelvic organ prolapse. Int Urogynecol J. 2012; 23(5): 579-584, doi: 10.1007/s00192-011-1593-y, indexed in Pubmed: 22083515.

33. Dietz HP, Shek KL. The quantification of levator muscle resting tone by digital assessment. Int Urogynecol J Pelvic Floor Dysfunct. 2008; 19(11): 1489-1493, doi: 10.1007/s00192-008-0682-z, indexed in Pubmed: 18690404.

34. Kruger JA, Dietz HP, Budgett SC, et al. Comparison between transperineal ultrasound and digital detection of levator ani trauma. Can we improve the odds? Neurourol Urodyn. 2014; 33(3): 307-311, doi: 10.1002/nau.22386, indexed in Pubmed: 23436235.
35. Dietz HP, Moegni F, Shek KL. Diagnosis of levator avulsion injury: a comparison of three methods. Ultrasound Obstet Gynecol. 2012; 40(6): 693-698, doi: 10.1002/uog.11190, indexed in Pubmed: 22605560.

36. Turel F, Shek KaL, Dietz HP. How Valid Is Tomographic Ultrasound Imaging in Diagnosing Levator and Anal Sphincter Trauma? J Ultrasound Med. 2019; 38(4): 889-894, doi: 10.1002/jum.14767, indexed in Pubmed: 30203420.

37. Baessler K, Christmann-Schmid C, Maher C, et al. Surgery for women with pelvic organ prolapse with or without stress urinary incontinence. Cochrane Database of Systematic Reviews. 2018; 2018(8), doi: 10.1002/14651858.cd013108.

38. Surkont G, Wlaźlak E, Petri E, et al. Standardized modified colposuspension--mid-term results of prospective studies in one centre. Ann Agric Environ Med. 2015; 22(2): 293-296, doi: 10.5604/12321966.1152082, indexed in Pubmed: 26094526.

39. Petri E. Czy kolposuspensja wciąż znajduje zastosowanie we współczesnej praktyce klinicznej? Medycyna Praktyczna - Ginekologia i Położnictwo. 2019; 5: 55-62.

40. Kluz T, Wlaźlak E, Surkont G. Transvaginal six-arm mesh OPUR in women with apical pelvic organ prolapse - analysis of short-term results, pelvic floor ultrasound evaluation. Ginekol Pol. 2017; 88(6): 302-306, doi: 10.5603/GP.a2017.0057, indexed in Pubmed: 28727128

41. Surkont G, Wlaźlak E, Suzin J. Long-term risk of complications after mid-urethral sling IVS implantation. Ann Agric Environ Med. 2015; 22(1): 163-166, doi: 10.5604/12321966.1141388, indexed in Pubmed: 25780848.

42. NICE guideline [NG123]. Urinary incontinence and pelvic organ prolapse in women: man-agement. Published date: 02 April 2019. Last updated: 24 June 2019. https://www.nice.org.uk/guidance/ng123/chapter/Recommendations\#assessing-pelvic-organ-prolapse.

43. Nager C, Brubaker L, Litman $\mathrm{H}$, et al. A Randomized Trial of Urodynamic Testing before Stress-Incontinence Surgery. N Engl J Med. 2012; 366(21): 1987-1997, doi: 10.1056/nejmoa1113595.

44. van Leijsen SAL, Kluivers KB, Mol BWJ, et al. Can preoperative urodynamic investigation be omitted in women with stress urinary incontinence? A non-inferiority randomized controlled trial. Neurourol Urodyn. 2012; 31(7): 1118-1123, doi: 10.1002/nau.22230, indexed in Pubmed: 22488817.

45. van Leijsen SA, Kluivers KB, Mol BW, et al. Dutch Urogynecology Consortium* ${ }^{*}$ Value of urodynamics before stress urinary incontinence surgery: a randomized controlled trial. Obstet Gynecol. 2013; 121(5): 999-1008, doi: 10.1097/AOG.0b013e31828c68e3, indexed in Pubmed: 23635736.

46. Govier FE, Pritchett TR, Kornman JD. Correlation of the cystoscopic appearance and functional integrity of the female urethral sphincteric mechanism. Urology. 1994; 44(2): 250-253, doi: 10.1016/s00904295(94)80142-8, indexed in Pubmed: 8048201.

47. Davis R, Jones JS, Barocas DA, et al. American Urological Association. Diagnosis, evaluation and follow-up of asymptomatic microhematuria (AMH) in adults: AUA guideline. J Urol. 2012; 188(6 Suppl): 2473-2481, doi: 10.1016/j.juro.2012.09.078, indexed in Pubmed: 23098784.

48. Chade DC, Shariat SF, Godoy G, et al. Clinical outcomes of primary bladder carcinoma in situ in a contemporary series. J Urol. 2010; 184(1): 74-80, doi: 10.1016/j.juro.2010.03.032, indexed in Pubmed: 20546806.

49. Haylen B, Maher C, Barber M, et al. An International Urogynecological Association (IUGA) / International Continence Society (ICS) joint report on the terminology for female pelvic organ prolapse (POP). Int Urogynecol J. 2016; 27(2): 165-194, doi: 10.1007/s00192-015-2932-1.

50. Maccioni F, Alt C. MRI of the Pelvic Floor and MR Defecography. IDKD Springer Series. 2018: 13-20, doi: 10.1007/978-3-319-75019-4_2. 